\title{
Biological diversity variations of pediatric acute leukemia in Brazil: contribution of immunophenotypic profiles to epidemiological studies
}

\author{
Diversidades biológicas da leucemia aguda em crianças no Brasil: contribuição de perfis \\ imunofenotípicos para estudos epidemiológicos
}

Maria S. Pombo-de-Oliveiral

José C. Cordoba ${ }^{2}$

Dora M. Alencar ${ }^{3}$

Mércia M. Campos ${ }^{1}$

Kadma Carriço ${ }^{I}$

Jane Dobbin ${ }^{1}$

Maria D. Dorea ${ }^{3}$

Regina Ferreira ${ }^{1}$

Núbia Mendonça ${ }^{3}$

Isis Q. Magalhães ${ }^{2}$
We describe the demographic and biological characteristics of 1,459 children with acute leukemia in Brazil to compare the effect of immunophenotypic differences with environmental factors that might be involved in the etiology of acute lymphoblastic leukemia (ALL). Combined morphological and immunological classifications were available for $96 \%$ of cases. Of these, $55 \%$ were B cell precursor ALL comprising pro$B A L L$ and $c-A L L, 15 \% T-A L L$ and $1.6 \%$ mature $B$-ALL. The proportion of Bp and TALL differed by race with $59 \%$ of whites being Bp-ALL and $60.7 \%$ of non-whites being T-ALL. Further inspection of these data revealed that the proportions of whites in each type (Bp/T-cell ALL) are almost identical in older children ( $60.3 \%$ and $59.3 \%$ respectively) but differ substantially in younger cases ( $<6$ years) with $63.6 \%$ of Bp-ALL and $37.3 \%$ of T-ALL being white. These results are consistent with excess incidence rates of $B p-A L L$ in young white children, although the distribution of $B p-A L L$ and $T$-ALL in each region was equitable with non-significant differences. The incidence rate of ALL was geographically variable, such as 2.2, 2.6 and 3.3/10 per year in Bahia, Rio and Brasilia, respectively. To evaluate if the pick of incidence could be related to viral infection, we observed that Bp-ALL was ascendant from late summer to winter and decreased in spring, whereas T-ALL had an increased peak in the fall. This study also provides background information for the epidemiology of childhood ALL in Brazil in which c-ALL could be associated with timing of exposure to infection and requires further investigations. Rev. bras. hematol. hemoter. 2005;27(1):21-26.

Key words: Acute lymphoblastic leukemia; immunophenotyping; ethnic origin; epidemiology.

\section{Introduction}

The distinction between acute leukemia according to lineage affiliation has important clinical, biological and epidemiological implications. Differences in the relative frequencies of subtypes of acute lymphoblastic leukemia (ALL) and acute myeloblastic leukemia (AML) in geographically diverse communities have been well-documented. ${ }^{1,2}$ Despite the great deal of well-designed therapeutic protocols, racial and ethnic differences are still playing a role in the survival of children with ALL, as has been reported by the Children's Cancer group therapeutic protocols. Multivariate analysis demonstrated that black and Hispanic children had worse outcomes when compared with white and Asian children after adjusting for prognostic risk factors. ${ }^{3}$ The distinct immunophenotype and gene expression profiling of ALL have been considered as prognostic determinants in this disease. ${ }^{4}$ In the last decade international data compared the relative frequencies of the different subtypes of ALL according to age, sex, ethnicity and social conditions, demonstrating a

\footnotetext{
${ }^{1}$ Divisão de Medicina Experimental, Serviço de Hematologia and Pediatria, Instituto Nacional de Câncer, Rio de Janeiro, Brasil.

${ }^{2}$ Departamento de Pediatria Onco-Hematológica do Hospital de Base, Brasilia, Brasil.

${ }^{3}$ Sociedade de Oncologia da Bahia, Salvador, Bahia, Brasil.
}

Correspondence: Maria S. Pombo de Oliveira, MD, PhD

Divisão de Medicina Experimental, Coordenação de Pesquisa do Instituto Nacional de Câncer

20230-130 - Rio de Janeiro-RJ - Brasil

Tel.: 552132331324 -e-mail: mpombo@inca.gov.br 
consistent selective deficit of common ALL (c-ALL) in children living in less developed countries. ${ }^{5,6}$ These data parallel the apparent increase in the incidence of c-ALL in the UK, USA and in Japan earlier in the last century and the significant association between the childhood peak of ALL and socioeconomic status within modern communities. ${ }^{7,8}$ Additional research in the United Kingdom and France has revealed highly significant associations with population mixes and other demographic features that are considered to reflect a possible infectious etiology. ${ }^{1,8}$ On the basis of these data, it has been suggested that childhood leukemia and particularly c-ALL, may involve an abnormal response to a common infection in previously unexposed individuals..$^{9-11}$ Greaves' hypothesized that the risks of childhood c-ALL are increased by an immune proliferative stress and this hypothesis was supported by different epidemiological studies with indications that the timing of exposure to common infections would be a major determinant to leukemogenesis process. ${ }^{12,13}$ A review of literature demonstrated that very few data are available regarding descriptive epidemiology and biological markers of childhood leukemia in South America. However, the more recent improvement of diagnostic techniques, including immunophenotyping and molecular biology, to assist in the Brazilian groups for ALL therapeutic trials have provided complete information regarding biological characteristics of leukemia subtypes in Brazil. Therefore, we analyzed data from a large epidemiological database and report here the result of the distribution of ALL subtypes in different Brazilian cities. These data contribute to the growing body of information concerning demographic factors associated with the etiology of childhood leukemia.

\section{Material and Methods}

\section{Subjects}

A series of 1,459 cases of ALL was referred to the Instituto Nacional de Câncer (Inca), Rio de Janeiro, Brazil during the period of January 1990 to September 2002 for leukemia classification by morphological and immunology and more recently by genetic molecular analysis. All cases were newly diagnosed and previously untreated children referred from hospitals involved in leukemia treatment. The referring physicians provided clinical and demographic data such as age, gender, educational level of the parents and place of birth. Cases evaluated in this study were derived from 4 sources: 1) children diagnosed in Rio de Janeiro, of which 150 were treated at Hospital do Cancer, Inca; 2) children consecutively diagnosed and treated at the Hospital de Base de Brasilia; 3) children clinically diagnosed and treated at Sociedade de Oncologia da Bahia, ascertained by consecutive referrals from the same region; 4) children consecutively diagnosed as acute leukemia, sent from other Brazilian Medical Centers and included in the therapeutic protocol of the Brazilian Group ofALL treatment [GBTLI]. ${ }^{14}$

\section{Demography}

For race differences we considered two major groups: (i) whites, children of Brazilians from European descendents; (ii) non-whites as a mixture of group including mulattos, mestizos, blacks, Brazilian Orientals and Amerindians. All these differences were evaluated by skin complexion rather than genetic backgrounds, and the allocation of white and non-white was based on the information provided by the referring services. The breakdown by age included patients who were 16 years old or less at the time of diagnosis. The under 16-year-old population from the regions where these patients came from is estimated at 12 million according to reports of Instituto Brasileiro de Geografia e Estatística, census 2000 (www.ibge.gov.br). The majority of the children in this series came from urban or semi-urban environments surrounding the largest cities with the population tending to be in the middle and lower level of the economic hierarchy where incomes were less than US\$10,000 per year. Our data represents $\sim 90 \%$ of the ascertainment of leukemia cases estimated for each Brazilian region and are validated by DATASUS, a registry with data from all ongoing clinical trails in pediatric oncology in Brazil (www.portal.saude. gov.br). The proportion of ALL cases included in this analysis was estimated in $\sim 85 \%$ of cases enrolled on the GBTLI clinical trials, considering the increasing adhesion of cases overtime.

\section{Leukemia classification}

In all cases included in this study, the initial diagnosis was established by the morphology of May-GrunwaldGiemsa and cytochemistry analysis stained in peripheral blood and bone marrow smears and meet the criteria for ALL according to FAB group criteria described elsewhere. ${ }^{15}$ Immunological classification of acute leukemia was based on criteria previously published by Catovsky et al [1990-1995] and EGIL classification [1996-2002] ${ }^{16,17}$ All patients' leukemia phenotypes were classified into five categories: pro-B-cell; common B and pre-B cell precursor ALL (c-ALL), T-ALL and B-ALL. Acute myeloid leukemia (AML) was defined immunologically by the expression of two of the following myelomonocytic markers: a-MPO, cCD13/CD33, CD117. For AML-M7 the membrane or cytoplasmic expression of CD41 and/or CD61 was important to define megakaryocytic lineage. To define a case as biphenotypic acute leukemia (Bi-AL) or acute leukemia with aberrant phenotype a score system was applied, in which the lineage specificity a-MPO, cCD3, cCD79b, cCD22 are marker that account for 2 points each. The co-expression of antigens in the same cell was required. Immunophenotyping was performed on fresh mononuclear cells separated by density gradient centrifugation or by red cells lyses solution and all samples had over $30 \%$ of blast cells. Antigen expressions were determined by direct or indirect immunofluorescence, evaluated by flow cytometry (BD-FACScan and/or Coulter Epics XL). A standard panel of $\mathrm{McAb}$ including anti-HLADr, CD34, CD7, CD19, CD10, 
CD33/13,CD14, TdT, aMPO, CD56 and cytoplasmic (c) CD3, cCD22 or CD79a, cCD13 and $\mu$-chain (cIg) were initially assessed and analysed by flow cytometry. CD117 and CD56 were introduced in the standard panel since 1999. We used a cut-off point for positivity at $20 \%$ (or above) of positive reacting cells. Standard cytogenetic and molecular analysis were performed in samples from institutions of Rio de Janeiro and Brasilia their results are described elsewhere. ${ }^{18,19}$

\section{Statistical analysis}

The total data sets were analyzed using the statistical package SPSS 11.0. In order to evaluate the variables frequencies, distributions and comparisons of proportions of cases, an extension of Pearson chi-square test was applied to detect statistically significant differences in demographic characteristics by region for all variables and for ALL subtypes. For all ALLs age groupings was considered as: 0-1 year, 2-5 years, 6-10 and 11-16 years. Further analyses regarding ALL were considering cases with known immunophenotype but excluding mature B-ALL; here the frequencies of $\mathrm{B}$-cell precursor $(\mathrm{Bp})$ and $\mathrm{T}$ cell cases were compared in the two racial groups (White/non-white). A multivariate analysis was performed by ANOVA (two-sided). Race was taken as the outcome variable and effect of $\mathrm{Bp} / \mathrm{T}$ ALL on proportions of whites vs. non-whites modeled with and without adjustment for gender and age. Incidence rate was calculated according to total number of cases (n) $\times 10^{5}$ divided by region population (p) $\times 5[\mathrm{I}=\mathrm{n} \times 10000 / \mathrm{p} \times 5]$.

\section{Results}

\section{Demographic data}

Table 1 shows the final classification of acute leukemia and frequency of different subtypes in 1,459 pediatric patients ascertained by consecutive referrals. There were 1,080 cases of ALL ( $70.4 \%)$ and 344 cases (23,6\%) of AML. There were 51 cases of "ALL" that had lymphoid morphology and SBB negativity but immunophenotyping could not be performed because of inadequate sample size. Twelve cases remain as undifferentiated leukemia due to absence of lineage specificity markers and 23 fulfill the criteria of B-ALL. These former groups and AML cases were excluded from analysis.

Because of the increased improvement at the level of leukemia diagnosis, we compared the data set in two different periods: 1990-95 and 1996-2002. We chose these cut-off points because of the remarkably increased proportion of cases enrolled in GBTLI clinical trials, that led the access to immunophenotyping techniques and EGIL criteria definitions. However, no statistical differences were found in the two series in the proportions of each race, gender, age group and leukemia subtype.

Distribution of ALL subtypes

Immunophenotypic classification was available in

\begin{tabular}{ccc}
$\begin{array}{c}\text { Table 1 } \\
\text { Classification of acute leukemia in children according to } \\
\text { morphology and immunophenotyping }\end{array}$ \\
\hline & $(\mathrm{N})$ & $(\%)$ \\
\hline Bp ALL & 808 & 55.4 \\
T-ALL & 221 & 15.1 \\
B-ALL & 23 & 1.6 \\
AML & 344 & 23.6 \\
AL* & 63 & 4.3 \\
\hline Total & 1459 & 100 \\
\hline
\end{tabular}

$\left(^{*}\right)$ Including cases of ALL with unknown immunophenotype and cases with aberrant phenotype

(96.2\%) patients withALL; of these 808 were Bp-ALL (55.4\%), 221 T-ALL (15.1\%) and 23 (1.6\%) B-ALL. CD19 and HLADr were expressed in all cases however, its expression in T-ALL was significantly less frequent than in Bp-ALL. CD34, a stem cell antigen, was expressed in $34.5 \%$ of the ALL cases in significantly more Bp-ALL than T-ALL cases $(\mathrm{p}=0.001)$. CD10 was positive in 673 cases of ALL, with $91.3 \%$ of Bp-ALL and $6.7 \%$ of T-ALL. Two hundred and thirty-four cases were tested for cytoplasmic -chain and the 62 tested positively. These pre-B cases were included in the c-ALL group for analysis. CD56 was positive in 12 (7\%) of 169 cases of ALL (Bp-ALL and T-ALL). The myeloid antigen expression CD13 and CD33 was more frequent in Bp-ALL than T-ALL ( $\mathrm{p}=0.001)$ but this difference was not statistically significant in CD13 or CD33.

We focused on Bp-ALL that comprises pro-B, c-ALL, pre-B ALL $(\mathrm{n}=808)$ and T-cell ALL subtypes $(\mathrm{n}=221)$ for a more detailed analysis of ALL. B-ALL and ALL with unknown immunophenotype are excluded from these analyses. The demographic characteristics of the patients studied are shown in Table 2. The Bp-ALL group showed the usual childhood peak (48\% aged 1-6 years) whereas the majority of T-ALL cases $(59.3 \%)$ were aged over 6 years. The overall male: female ratio was 1.2:1 and the white: non-white ratio for the total series was 1.4:1, but the proportions of each race differed by age group and leukemia subtype. These distributions were different when the two groups were analyzed separately: for Bp-ALL the ratio of male: female was 1.1: 1 whereas for TALL the male: female ratio was 1.9:1 $(\mathrm{p}=0.001)$. The proportion of Bp and T-ALL differed by race with 77\% of whites being Bp-ALL and $60.7 \%$ of non-whites being T-ALL. These differences were highly statistically significant $(p<0.001$ in the unadjusted analyses, 0.002 adjusting for age in standard groups). Further inspection of these data reveals that the proportions of whites in each type (Bp/T-cell ALL) are almost identical in the older children $(60.3 \%$ and $59.3 \%$ white respectively, over 6 years) but differ substantially in the younger cases, with $63.6 \%$ of Bp-ALL and $37.3 \%$ of T-ALL being white. These results are consistent with excess incidences rates of Bp-ALL in young white children. The 


\begin{tabular}{|c|c|c|c|c|c|c|}
\hline \multicolumn{7}{|c|}{$\begin{array}{c}\text { Table } 2 \\
\text { Demographic features and distribution of acute leukemias in different subtypes }\end{array}$} \\
\hline & $\begin{array}{l}\text { Total } \\
n \quad(\%)\end{array}$ & $\begin{array}{l}\text { BpALL } \\
\text { n }(\%)\end{array}$ & $\begin{array}{l}\text { T-ALL } \\
\mathrm{n} \quad(\%)\end{array}$ & $\begin{array}{l}\mathrm{AML} \\
\mathrm{n} \quad(\%)\end{array}$ & $\begin{array}{l}\text { ALs* } \\
n \quad(\%)\end{array}$ & $\mathrm{p}$ \\
\hline Age range: $0-1$ & $286(20)$ & $162(20)$ & $14(6.3)$ & 95 (27.6) & $15(17.5)$ & \\
\hline $2-5$ & $602(41)$ & $388(48)$ & $76(34.4)$ & $101(29.4)$ & $37(43)$ & 0.001 \\
\hline $6-10$ & 265 (18) & $129(16)$ & $55(24.9)$ & $60(17.4)$ & $21(24.4)$ & \\
\hline $11-16$ & $306(21)$ & $129(16)$ & $76(34.4)$ & $88(25.6)$ & $13(15.1)$ & \\
\hline Gender: Boys & $820(56.2)$ & $433(53.6)$ & $145(65.6)$ & $193(56.1)$ & $49(57)$ & 0.001 \\
\hline Girls & $639(43.8)$ & $375(46.4)$ & $76(34.4)$ & $151(43.9)$ & $37(43)$ & \\
\hline Race: Whites & $812(55.7)$ & $477(59)$ & 87 (39.4) & $198(57.6)$ & $50(58.1)$ & 0.001 \\
\hline Non-Whites & $647(44.3)$ & 331 (41) & $134(60.6)$ & $146(42.4)$ & $36(41.9)$ & \\
\hline TOTAL & $1459(100)$ & $808(55.3)$ & $221(15.1)$ & 344 (23.6) & $86(5.8)$ & \\
\hline
\end{tabular}

(Figure 1). The ratio was 1.16(1.121.20) $95 \% \mathrm{CI}$ and there was an excess of Bp-ALL cases $(16 \%)$ during the winter for the entire group. Considering that the c-ALL group ratio was 1.05 (1.00-1.10), 95\% CI, there was no significant correlation between the two variables Bp-ALL and T-ALL regarding seasonality for any Brazilian region independently.

\section{Discussion}

Brazil is a continental country with a tropical climate and heterogeneous population. The opportunities seen in industrial work and the level of modernization with a better standard of living have

\section{Table 3}

Distribution of ALL subtypes in different Brazilian geographical regions

\begin{tabular}{cccccc} 
Bp-ALL & $368(53.9)$ & $211(62.2)$ & $163(53.4)$ & $66(49.6)$ & 0.005 \\
T-ALL & $102(14.9)$ & $50(14.7)$ & $47(15.4)$ & $22(16.5)$ & $n s$ \\
AML & $165(24.1)$ & $67(19.7)$ & $78(25.5)$ & $34(25.5)$ & $n s$ \\
AL $^{*}$ & $47(6.8)$ & $11(3.2)$ & $17(5.5)$ & $11(8.2)$ & $n s$ \\
\hline
\end{tabular}

RJ= Rio de Janeiro; DF= Brasilia; $B A=$ Salvador, Bahia ;

OS are cases diagnosed in Rio but of children originating from other regions of Brazil ascertained without consecutive referral;

$\left.{ }^{*}\right)$ cases of ALL with unknown immunophenotyped

distribution of ALL subtypes in different regions of Brazil is shown in table 3. The distribution of Bp-ALL and T-ALL cases was equitable with non-significant differences when examining ALL distribution by region, however Bp-ALL were more evident from Brasilia than the other regions ( $\mathrm{p} 0.005$ ).

\section{Incidence rates and seasonality}

The average annual incidence rates according to age and sex in each region were calculated among children less than 16 years of age at diagnosis. The variation of population in Rio de Janeiro, Salvador and Brasilia allowed us to estimate the incidence rate of ALL at 2.5, 2.7 and 3.3/10 cases per year, with expected cases in the general population of 66,74 and 81 cases per year, respectively. The overall rate estimated included all children without race-specificity and corresponding to the population in each Brazilian region.

Seasonality was also analyzed taking into account the frequency of newly diagnosed cases per month during the study. Bp-ALL was ascendant from late summer to winter (December-August) and decreases in spring (SeptemberOctober), whereas T-ALL had an increased peak in fall increased notably in the last decades. A previous epidemiological study reported a low incidence of childhood leukemia for areas of Brazil when compared with USA and European Countries. ${ }^{20}$ However, these results were based on registration data that suffered from inaccuracies in classification of broad subtypes of ALL. At that time ALL was not routinely included in epidemiological data sets with specific immunophenotypes and factors such as high mortality rate in children under 5 years of age due to poor healthcare underlie the lack of progress in leukemia studies. Since a marked improvement occurred in the healthcare system in Brazil during these last decades, we believe that in the present data, under diagnosis or misdiagnosis did not contribute to change ALL frequencies and it is unlikely that our results represent a bias by subtype and/or social condition in the regions analysed here. The variation of population younger than 16 years in Rio de Janeiro, Salvador and Brasilia allowed us to estimate incidence rates for ALL at 24.5, 26.5 and $33.1 / 10^{6}$ per year respectively. Although slightly different incidence rates of ALL are demonstrated in this series of children, the subtypes of ALL,

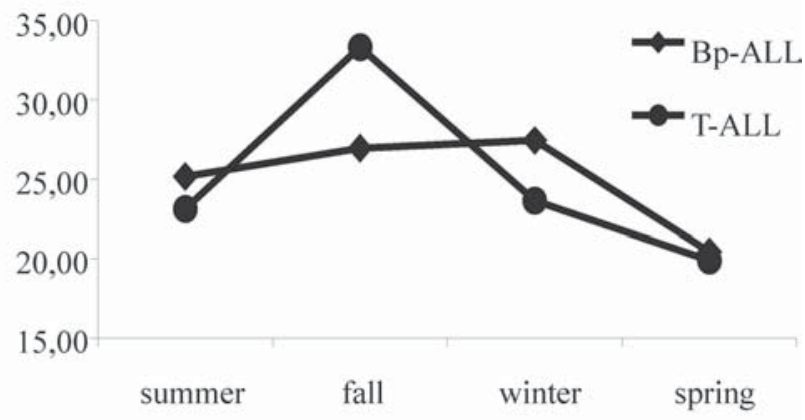

Figure 1. Distribution of ALL subtypes according to seasonality 
the gender, ratio and age distributions of ALL are similar to those reported for other Brazilian regions. ${ }^{21}$ One exception is that our age incidence profile for c-ALL appears to be slightly broader (Figure 2) with similar distribution however, recorded in another series of Brazilian patients ${ }^{22}$ and in reports from Chile ${ }^{1}$ and Nicaragua. ${ }^{23}$

Although we initially expected that different subtypes of Bp-ALL and T-ALL would be present in different regions of Brazil based on factors determined by race (non-whites are more prevalent in Bahia than other regions) we did not demonstrate these differences. The distribution of Bp-ALL and T-ALL cases was equitable with non-significant differences when examining ALL distribution by region. However, one important finding in this study is the biased distribution or relative frequency of ALL subtypes in relation to racial groups. These immunophenotypic differences often reflect genetic distinctions. Whether this translates into an absolute deficit of c-ALL incidence in non-white Brazilian children requires reflection as to exactly what racial differences represent to genetic susceptibility for ALL in Brazilian population. According to a study performed by Parra et $\mathrm{al}^{2,}$ skin complexion is a poor predictor of race and Brazilians constitute a trihybrid population of European, African and Amerindian roots with an admixture of population-specific alleles. Analyzing mtDNA, they found a 33\% Amerindian and $28 \%$ African contribution to white Brazilians. ${ }^{23}$ Therefore, this phylographic heterogeneity is still difficult to fit into the framework composed by the gene pool and environmental exposure in the etiology of acute leukemia in Brazil. For instance, the karyotype profiles and recurrent abnormalities found in a series of 100 consecutive newly diagnosed cases of ALL in Rio de Janeiro ( $\sim 50$ cases were included in this manuscript), is similar to those described by other European groups. Magalhães et al, reached a conclusion by demonstrating that the frequency, age distribution and clinical features of $20 \%$ of TEL/AML1 fusion genes in c-ALL were similar to those found in patients from the US and Europe ${ }^{18,19}$ The frequency of "anomalous" markers such as myeloid associated antigens (CD33/CD13) detected in ALL were

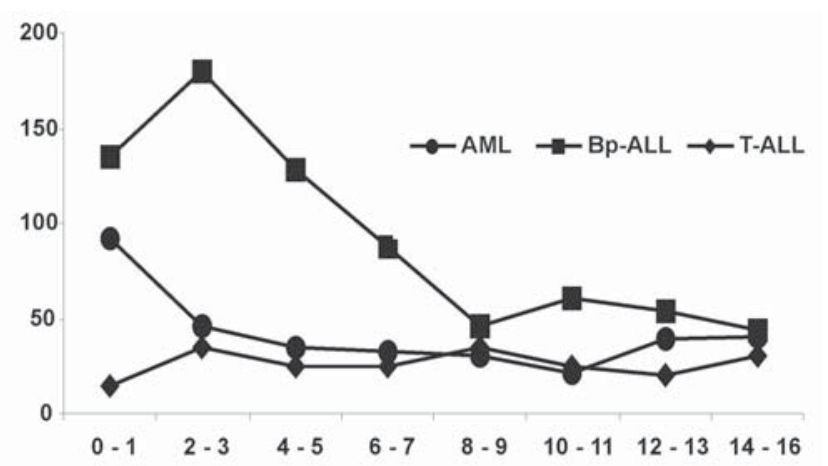

Figure 2. Age distribution of ALL subsets among 1459 Brazilian children similar to those described in different group's therapeutic protocols. Although inherited genetic factors cannot be entirely ruled out, our findings favor the suggestion that the immunophenotype characteristics is more related to age at diagnosis and it is likely that these differences in ALL subtypes are real, reflecting socio-economic and life-style factors, rather than the putative race suggested by the appearance of individuals.

An increased risk of ALL was observed in MTHFR1298AC in children from less developd regions in Brazil. An interesting finding in our series of cases is the seasonal variation in the onset of leukemia. Despite of different climate variations from Northeast to Southeast Brazil, we observed a peak in fall-winter corresponding to the months from March to August, in the clinical onset of the Bp-ALL and T-ALL (increasing rate of influenza, respiratory infection, coksakie), and a decrease in the incidence of Bp-ALL cases in spring/summer (increasing rate of rush fever, mumps, PVB19, EBV and CMV infections). These findings are just the opposite of data from USA survey where, there were a spring/summer excess in the onset of leukemia. ${ }^{25}$ Some recent studies in USA and UK are controversial. ${ }^{26}$ The seasonality in the framework of etiology of ALL displays a possible causative agent exposure, specially but not exclusively viral infections, during certain periods of time, that provide support for an infectious etiology for c-ALL. ${ }^{9}{ }^{10}$ In Greaves' hypothesis, the epidemiological evidence based on certain demographic characteristics that include geographic diversity and seasonality, is substantial and persuasive. In his model these associations could be related to the immune system, because an absence of early exposure to common or endemic infections and absence of an antigenetic challenge during infancy leaves the immune system at an inefficient modulation. This deficient immunological repertoire could lead either to an inadequate protective immune response or a hyper-reactive unbalanced response. The late reaction would promote a preexisting mutant $\mathrm{B}$ precursor cell usually expressing CD10, that could arise in utero plus a proliferative stress which would convert a pre-leukemic state into a clinical acute leukemia. ${ }^{12}$ Regionally our observations support Greaves' hypothesis, as Bahia has a lower incidence of c-ALL (16 per $10^{5}$ ) and is a region where some tropical diseases are endemic (leishmaniasis, malaria and high prevalence of HTLVI infection), the family size is numerous and prolonged breastfeeding is very characteristic, whereas Brasilia has the highest incidence rate and is considered a "new town" with a populational admixture and a great degree of mobility. This study provides the background information and opportunity for a more systematic study of the epidemiology of childhood ALL in Brazil in which factors associated with genetic susceptibility and/or polymorphism differences, patterns of infection in infancy, and a variable lifestyle would be further extended to evaluate their relevance to the leukemia pathogenesis. 


\section{Resumo}

Os autores descrevem as características biológicas de 1.459 crianças com leucemias agudas no Brasil, para comparar os efeitos de diferentes perfis imunofenotipicos com fatores ambientais que podem estar associados à etiologia das leucemias linfoblásticas agudas (LLA). As classificações morfológicas e imunofenotípicas combinadas foram aplicadas em $96 \%$ dos casos. Nestes, 55\% foram classificados como $L L A$ de células B precursoras (LLA-Bp) que compreendem LLA-pro-B e LLA-comum, 15\% LLA-T, e 1,6\% LLA-B. A proporção de $L L A-B p$ e $L L A-T$ difere entre si quanto à raça, com 59\% das LLA-Bp em crianças brancas, enquanto 60,7\% LLA-T em crianças não-brancas. No entanto, as análises proporcionais de brancos versus não brancos para cada subtipo, quando ajustadas por idade, são semelhantes em crianças maiores de 6 anos (60,3\% LLABp e 59,3\% LLA-T), mas diferem substancialmente em crianças menores, com 63,6\% de LLA-Bp e 37,3\% de LLA-T em brancos (0,0001). Estes resultados são consistentes com excesso de $L L A-B p$ em crianças brancas mais jovens, embora a distribuição entre LLABp e LLA-T em cada região seja semelhante sem significado estatistico. As taxas de incidências de LLA calculadas para cada região variaram de 2,2, 2,6 e 3,3/10 casos por ano para Bahia, Rio de Janeiro e Brasília, respectivamente. Para avaliar se o pico de incidência observado de LLA-Bp estaria relacionado com incidência de infeção viral, nós observamos que LLA-Bp apresentou uma curva ascedente de casos no verão e inverno, enquanto LLA-T apresentou pico de incidência no outono. Este estudo adiciona informações sobre epidemiologia de leucemias agudas no Brasil, no qual sugere que o subtipo LLA-comum poderia estar associado com tempo de exposição a infecção viral requerendo futuras análises específicas. Rev. bras. hematol. hemoter. 2005;27(1):21-26.

Palavras-chave: Leucemia linfóide aguda; imunofenotipagem; etnia; epidemiologia.

\section{Acknowlegments}

We are grateful to all referring physicians who provided samples and data of children included in this work. We are very grateful to Prof. Mel Greaves who helped with comments and all technical aspects of data described in the manuscript.

\section{References}

1. Greaves MF, Colman SM, Beard MEJ et al. Geographical distribution of acute lymphoblastic leukaemia subtypes: second report of the Collaborative Group Study. Leukemia 1993;7:27-34.

2. Linet MS, Devesa SS. Descriptive epidemiology of childhood leukemia. Brit J Cancer 1991;63:424-429.

3. Bhatia S, Sather HN, Heerema NA et al. Racial and ethnic differences in survival of children with acute lymphoblastic leukemia. Blood 2002;100:1.957-64.

4. Pui CH, Campana D, Evans WE. Childhood acute lymphoblastic leukaemia - current status and future perspectives. Lancet Oncol 2000;2:597-607.

5. Bowman WP, Presbury G., Melvin SL et al. A comparative analysis of acute lymphoblastic leukemia in white and black children: presenting clinical features and immunological markers. In Pathogenesis of Leukemia and Lymphomas: Environmental Influences, P.P 169-179, Ed By Magrath It, O'Connor Gt, Ramont B. Raven Press, NY, 1984.
6. Kamel AM, Assem MM, Jaffe ES et al. Immunological phenotype pattern of acute lymphoblastic leukaemia in Egypt. Leuk Res 1989;13:519-525.

7. Nishi M, Miyaki H. A case-control study of non-T cell acute lymphoblastic leukemia in children in Hokkaido, Japan. J Epidemiol Commun Health 1989;43:352-355.

8. Perrilat F, Clavel J, Auclerc MF et al. Day-Care, Early common infections and childhood acute leukemia: A multicentre French case-control study. Br J Cancer 2002;86:1.064-69.

9. Greaves MF, Alexander FE. An infections etiology for common acute lymphoblastic leukemia In childhood? Leukemia 1993;7:349-360.

10. Kinlen LJ. Epidemiological evidence for an infective basis in childhood leukaemia. Brit J Cancer 1995; 71:1-5.

11. Smith M. Considerations on a possible viral etiology for B-precursor acute lymphoblastic leukemia of childhood. J Immunother 1997;20:89-100.

12. Greaves M. Molecular genetics, natural history and the demise of childhood leukaemia. Eur J Cancer 1999;35:173-185.

13. Chan LC, Lam TH, Li CK et al. Is the timing of exposure to infection a major determinant of acute lymphoblastic leukaemia in Hon Kong? Pediatric and Perinatal Epidemiology 2002;16:154-165.

14. Brandalise S, Odone-Filho V, Pereira WV et al. Treatment results of three consecutive Brazilian cooperative childhood ALL protocols: GBTL-80,-82 and-85. Leukemia 1993;7 (suppl):142-145.

15. Bain BJ. Leukaemia Diagnosis. Blackwell Science, London. 1997.

16. Catovsky D, Matutes E, Buccheri V et al. A classification of acute leukaemia for the 1990s. Ann Hemtol 1991;62:16-21.

17. European Group for the immunological characterization of acute leukemias: Bene MC, Castoldi G, Knapp W, et al. Proposals for the immunological classification of acute leukemias. Leukemia 1995;9:1783-86.

18. Magalhães IQ, Pombo-De-Oliveira MSP, Bennett CA et al. TELAML1 fusion gene frequency in paediatric acute lymphoblastic leukaemia in Brazil. Br J Haematol 2000; 111:204-207.

19. Silva MLM, Souza MHO, Ribeiro RC et al. Cytogenetic Analysis of 100 consecutive newly diagnosed cases of ALL in Rio de Janeiro. Cancer Genetics and Cytogenetics 2002; 137: 85-90.

20. Parkin DM, Stiller CA, Draper GJ, Bieber CA. The International incidence of childhood cancer. Int J Cancer 1988; 42: 511-520.

21. Howard SC, Pedrosa M, Lins M et al. Establishment of a pediatric oncology program and outcomes of childhood acute lymphoblastic leukemia in a resource-poor area. JAMA 2004; 291:2.471-2.475

22. Rego EM, Garcia AB, Viana SR, Falcão RP. Characterization of acute lymphoblastic leukemia subtypes in Brazilian patients. Leuk Res 1996;20:349-355.

23. Malta A, Baez F, Floresa A et al. Childhood acute lymphoblastic leukemia. Features at the onset in patients in Monza (Italy) and Managua (Nicaragua) International Journal Of Pediatric Hematology/ Oncology 1997; 4:121-125.

24. Parra FC, Amado RC, Lambertucci JR et al. Color and genomic ancestry In Brazilians. Proc Natl Ac Sci 2003;100:177-182.

25. Fekety FR, Carey JJH. Season and the onset of acute childhood leukaemia. Md State Med 1969;18:73-77.

26. Badrinath P, Day NE, Stockton D. Seasonality in the diagnosis of acute lymphocytic leukaemia. Br J Cancer 1997;75:1.711-1.713.

Avaliação: Editor e dois revisores externos.

Conflito de interesse: não declarado

Recebido: 18/01/05

Aceito após modificações: 10/03/05

Recursos financeiros: This work was supported by CNPq n ${ }^{\circ} 550891 / 01-3$ and Faperj $n^{\circ}$ E-26/152.016/2000 grants, and INCa-FAF/Swiss Bridge Foundation $\mathrm{n}^{\circ}$ 230150-4. 